\title{
Factors associated with body image distortion in Korean adolescents
}

\author{
This article was published in the following Dove Press journal: \\ Neuropsychiatric Disease and Treatment \\ 13 May 2014 \\ Number of times this article has been viewed
}

\author{
Mi-Yeul Hyun' \\ Young-Eun Jung² \\ Moon-Doo Kim ${ }^{2}$ \\ Young-Sook Kwak ${ }^{2}$ \\ Sung-Chul Hong ${ }^{3}$ \\ Won-Myong Bahk ${ }^{4}$ \\ Bo-Hyun Yoon ${ }^{5}$ \\ Hye Won Yoon ${ }^{6}$ \\ Bora Yoo ${ }^{6}$ \\ 'College of Nursing, Jeju National \\ University, Jeju, Korea; ${ }^{2}$ Department \\ of Psychiatry, School of Medicine, \\ Jeju National University, Jeju, Korea; \\ ${ }^{3}$ Department of Preventive Medicine, \\ School of Medicine, Jeju National \\ University, Jeju, Korea; ${ }^{4}$ Department \\ of Psychiatry, Yeouido St Mary's \\ Hospital, College of Medicine, \\ The Catholic University of Korea, \\ Seoul, Korea; ${ }^{5}$ Department \\ of Psychiatry, Naju National Hospital, \\ Naju, Korea; 'School of Medicine, \\ Jeju National University, Jeju, Korea
}

Purpose: Body image incorporates cognitive and affective components as well as behaviors related to own body perception. This study evaluated the occurrence of body image distortion and its correlates in Korean adolescents.

Methods: In a school-based cross-sectional survey, a total of 2,117 adolescents were recruited. They filled out self-completing questionnaires on body image distortion, eating attitudes, and behaviors (Eating Attitude Test-26) and related factors.

Results: Body image distortions were found in 51.8 percent of adolescents. Univariate analyses showed that boys and older adolescents had higher rates of body image distortion. In the multivariate analyses, body image distortion was associated with high risk for eating disorders (odds ratio $[\mathrm{OR}]=1.69 ; 95 \%$ confidence interval $[\mathrm{CI}] 1.11-2.58 ; P=0.015$ ) and being over weight $(\mathrm{OR}=33.27 ; 95 \%$ CI 15.51-71.35; $P<0.001)$ or obese $(\mathrm{OR}=9.37 ; 95 \%$ CI 5.06-17.34; $P<0.001)$.

Conclusion: These results suggest that body image distortion is relatively common in Korean adolescents, which has implications for adolescents at risk of developing eating disorders.

Keywords: body image distortion, high risk for eating disorders, Korean adolescent

\section{Introduction}

In adolescents, changes in physical appearance and body shape during puberty can be a sensitive and important subject. Issues with body image and body satisfaction can influence eating behaviors and motivation toward weight control. ${ }^{1}$ Body image distortion and dissatisfaction in adolescents may play a crucial role in the development of pathogenic behaviors such as excessive dieting, exercising, and purging. They can lead to serious psychological and medical problems such as eating disorders (eg, anorexia nervosa and bulimia nervosa). ${ }^{2,3}$

Body image distortion is considered as a multidimensional pattern consisting of cognitive and affective components (concerns and feelings about the body) and behaviors related to own body perception. Body image distortion can have two meanings: one is to have a distorted image of one's body, which is a problem of recognition, and the other is to have an emotional response about one's physical condition ie, not happy. ${ }^{2}$ Body image distortion is recognized to be a core and often persistent symptom in EDs defined as disorders in which there is extreme concern with the control of body weight and shape, followed by grossly inadequate, capricious, or hectic food intake. ${ }^{4}$

Although various estimates of the prevalence of EDs $(0.3 \% \sim 3.0 \%)$ have been reported based on studies using different approaches in different settings, it is evident that the prevalence of EDs is increasing worldwide. ${ }^{5-9}$ EDs are associated with numerous serious medical consequences such as electrolyte disturbance,

\footnotetext{
Correspondence:Young-Eun Jung/ Moon-Doo Kim Department of Psychiatry, School of Medicine, Jeju National University, I5 Aran I 3-gil, Jeju 690-756, Korea Tel +82647171234 Fax +82 647171849 Email jyejye77@daum.net/mdkim66@ jejunu.ac.kr
}

submit your manuscript | www.dovepress.com Dovepress 
cardiac arrhythmias, amenorrhea, and osteoporosis. In addition, EDs are chronic conditions that impact negatively on psychosocial functioning. Feelings of ineffectiveness, low self-esteem, social isolation, depressed mood, and anxiety are common and, furthermore, poor psychosocial functioning is complicated by psychiatric comorbidity, such as major depression, suicidality, obsessive compulsive disorder, and substance abuse. ${ }^{10,11}$ EDs are related to physical, psychological, and social maturity in adolescents, and the peak age of ED onset is during adolescence; over $90 \%$ of patients with EDs are diagnosed before the age of 25 years. ${ }^{12}$ There has begun to be an awareness of problems related to EDs in adolescence and their importance, and disturbed eating attitudes and behaviors in a critical period during which major development happens are thought to be a risk factor for chronic EDs in adulthood.

Rapid growth and globalization in developed Asian countries, including Korea, have led to sociocultural changes such as notions of beauty, popularization of dieting, and growing concerns about obesity. First of all, these changes warn of the possibility of an increasing prevalence of body image distortion and EDs. According to a literature review, the number of subjects with EDs or abnormal eating attitudes is increasing faster in non-Western countries. ${ }^{13}$ Recent Asian studies, including of Korea, ${ }^{14}$ Taiwan, ${ }^{15}$ and Hong Kong, ${ }^{16,17}$ found a high prevalence of abnormal eating behaviors in adolescents. However, very little is known about the prevalence of body image distortion at the population level among any age group. This cross-sectional study was designed to assess the prevalence and to explore the factors (sociodemographic characteristics and clinical features) associated with body image distortion among Korean adolescents. It especially investigates the associations among body image distortion, disturbed eating behaviors, body satisfaction, and current weight status.

\section{Material and methods Participants}

Of a total of 2,310 eligible subjects, 2,139 (92.6\%) adolescents were recruited from four middle schools (8th grade, age range: 13-14 years) and three high schools (10th grade, age range: 15-16 years) located in the Jeju Special Self-Governing Province, Republic of Korea. The target schools volunteered to participate in the study, and we selected them to represent typical Korean public schools in the urban area. After gaining approval, researchers visited the schools, explained the purpose of the study to the students and teachers, and gained their consent. The researchers also sent the parents letters introducing the purpose of the study.
The letter included a statement that parents could freely refuse to respond if they did not agree with the purpose of the study. This study was approved by the Jeju National University Hospital Review Board. Twenty-two subjects were excluded because their responses were incomplete, thus leaving a total of 2,117 subjects for the analyses.

\section{Assessment}

\section{Sociodemographic characteristics}

This study used a self-report questionnaire concerning aspects of home and school. The data on age, sex, school grade, family structure, parental education level, and body satisfaction using a three-scale measure were obtained. Body mass index $\left(\mathrm{BMI}=\right.$ weight $[\mathrm{kg}] /$ squared height $\left.\left[\mathrm{m}^{2}\right]\right)$ was calculated based on self-reported weight and height. According to data from the 2007 Korean National Growth Charts on BMIs by age and sex, ${ }^{18}$ adolescents were classified as underweight (BMI $<15$ th percentile), normal weight (15th percentile $\leq$ BMI $<85$ th percentile), overweight (85th percentile $\leq$ BMI $<95$ th percentile), and obese (BMI $\geq 95$ th percentile).

\section{Body image}

The somatotype drawings typically consist of a set of discrete schematic figures, ranging from emaciated (1) to obese (9). From a series of nine somatotype drawings, subjects were requested to select the body shape that would be their ideal body size (ideal) and to select the body shape that represents their current body size (current). ${ }^{19}$ In our study, numbers 1-9 were assigned to groups based on actual BMI values. "Body image distortion" was defined as subjects' choice difference of two or more numbers from the actual groups. ${ }^{20}$

\section{Eating attitudes and behaviors}

The Eating Attitudes Test-26 (EAT-26) is a widely used tool for diagnosing adolescents with disturbed eating attitudes and behaviors. ${ }^{21,22}$ The EAT-26 is a self-report measure, and the scores are ranked on a six-point Likert scale. A validated Korean version of the EAT-26 for adolescents was used in this study. In a Korean study, EAT-26 scores $\geq 20$ are frequently associated with disturbed eating attitudes and behaviors, and may identify individuals with EDs. ${ }^{23}$ In our study, high risk for EDs was defined as EAT-26 scores $\geq 20 .{ }^{23}$

\section{Depression}

The Beck Depression Inventory was used to measure depressive symptoms. The Beck Depression Inventory consists of 21 items to measure the subjective severity and various symptoms of depression. ${ }^{24}$ The presence of depression 
was represented by scores of 16 and above, according to a previous validation study in a general population of Korea. ${ }^{25}$

\section{Data analysis}

The Pearson chi-square test and independent $t$-test were used to compare the proportions and means of the independent variables versus dependent variables. For the correlates analyses, univariate associations were investigated between independent variables and body image distortion. Factors potentially associated with body image distortion on univariate analyses were then entered simultaneously into a logistic regression model to assess independence. Odds ratios (ORs) and 95\% confidence intervals (CIs) were derived from a series of logistic regression analyses. All statistical analyses were performed using SPSS (version 18.0; IBM Corporation, Armonk, NY, USA), and statistical significance was determined using an $\alpha$ level of 0.05 (two-tailed tests).

\section{Results}

Among the total 2,117 students, there were 1,285 boys (60.7\%) and 832 girls (39.3\%). The mean \pm standard deviation age was $14.4 \pm 1.0$ years. There were 1,446 middle school students (8th grade, age range: 13-14 years) and 671 high school students (10th grade, age range: 15-16 years). Most of the adolescents lived with their father and mother together (86.7\%), and $63.7 \%$ of fathers and $51.3 \%$ of mothers were college graduates. Table 1 shows the characteristics of the subjects by sex. Girls reported more body dissatisfaction than boys. There were no differences by sex in demographic variables.

In this study, body image distortion was found in 51.8\% of adolescents. There were significant differences in prevalence of body image distortion by age (13-14 years: $49.7 \%$, 15-16 years: 54.8\%) and sex (boys: $55.3 \%$, girls: $45.2 \%$ ). Boys and older adolescents had higher rates of body image distortion. In univariate analyses, there were significant associations between body image distortion and high risk for EDs, body dissatisfaction, and current weight status (Table 2).

Table 3 displays multivariate associations between independent factors and body image distortion. After adjustment for age and sex, body image distortion was significantly associated with high risk for EDs (OR $=1.69 ; 95 \% \mathrm{CI}$ $1.11-2.58 ; P=0.015)$, and being overweight $(\mathrm{OR}=33.27 ; 95 \%$ CI $15.52-71.35 ; P<0.001)$ or obese $(\mathrm{OR}=9.37 ; 95 \% \mathrm{CI}$ 5.06-17.34; $P<0.001)$.

Table I Characteristics of the subject by sex

\begin{tabular}{|c|c|c|c|}
\hline & Boys $(n=I, 285)^{a}$ & Girls $(n=832)^{a}$ & $P$-value \\
\hline Age, y & & & 0.080 \\
\hline $13-14$ & $896(69.7 \%)$ & $550(66.1 \%)$ & \\
\hline $15-16$ & $389(30.3 \%)$ & $282(33.9 \%)$ & \\
\hline Family structure & & & 0.573 \\
\hline Living with both parents & I,III (87.I\%) & $713(86.2 \%)$ & \\
\hline Living with one parents & 165 (12.9\%) & $114(13.8 \%)$ & \\
\hline Paternal education & & & $0.94 I$ \\
\hline$>12 y$ & $683(63.7 \%)$ & $464(63.8 \%)$ & \\
\hline$\leq 12 y$ & $390(36.3 \%)$ & $263(36.2 \%)$ & \\
\hline Maternal education & & & 0.456 \\
\hline$>12 y$ & $549(51.1 \%)$ & 389 (52.9\%) & \\
\hline$\leq 12 y$ & $526(48.9 \%)$ & 347 (47.1\%) & \\
\hline Current weight status & & & 0.180 \\
\hline Normal weight & $\mathrm{I}, 044$ (8I.2\%) & $697(83.8 \%)$ & \\
\hline Underweight & 47 (3.7\%) & $31(3.7 \%)$ & \\
\hline Overweight & 134 (10.4\%) & $63(7.6 \%)$ & \\
\hline Obese & $60(4.7 \%)$ & $4 \mathrm{I}(4.9 \%)$ & \\
\hline Body dissatisfaction & & & $<0.00 I^{b}$ \\
\hline Low & $317(24.8 \%)$ & $83(10.0 \%)$ & \\
\hline Moderate & 535 (4I.9\%) & 287 (34.6\%) & \\
\hline Extreme & $425(33.3 \%)$ & $459(55.4 \%)$ & \\
\hline \multicolumn{4}{|l|}{ Somatotype drawings ${ }^{c}$} \\
\hline No of current body shape & $4.2 \pm 1.5$ & $4.4 \pm 1.3$ & $0.006^{b}$ \\
\hline No of ideal body shape & $4.1 \pm 0.9$ & $3.5 \pm 0.8$ & $<0.00 \mathrm{I}^{\mathrm{b}}$ \\
\hline
\end{tabular}

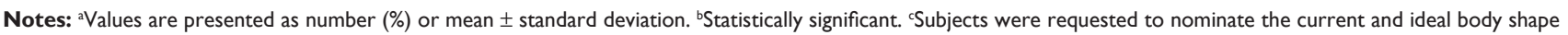
from a series of somatotype drawings, which ranged from extremely thin (I) to obese (9).

Abbreviation: $y$, years. 
Table 2 Comparisons of characteristics between subjects with and without body image distortion

\begin{tabular}{|c|c|c|c|}
\hline & \multicolumn{2}{|c|}{ Body image distortion } & \multirow[t]{2}{*}{$P$-value } \\
\hline & Yes $(n=I, 087)^{a}$ & No $(n=I, 030)^{a}$ & \\
\hline Age, y & & & $0.028^{b}$ \\
\hline $13-14$ & $719(66.1 \%)$ & 727 (70.6\%) & \\
\hline $15-16$ & $368(33.9 \%)$ & $303(29.4 \%)$ & \\
\hline Sex & & & $<0.001^{\mathrm{b}}$ \\
\hline Boys & $711(65.4 \%)$ & 574 (55.7\%) & \\
\hline Girls & $376(34.6 \%)$ & $456(44.3 \%)$ & \\
\hline Family structure & & & 0.829 \\
\hline Living with both parents & $94 I$ (86.9\%) & $883(86.6 \%)$ & \\
\hline Living with one parents & $142(13.1 \%)$ & 137 (13.4\%) & \\
\hline Paternal education & & & 0.166 \\
\hline$>12 y$ & $615(65.2 \%)$ & $532(62.1 \%)$ & \\
\hline$\leq 12 y$ & $328(34.8 \%)$ & $325(37.9 \%)$ & \\
\hline Maternal education & & & 0.636 \\
\hline$>12 y$ & 495 (52.3\%) & $443(5 \mid .2 \%)$ & \\
\hline$\leq 12 y$ & 45 I (47.7\%) & $422(48.8 \%)$ & \\
\hline Current weight status & & & $<0.00 I^{b}$ \\
\hline Normal weight & 769 (70.7\%) & 972 (94.4\%) & \\
\hline Underweight & $39(3.6 \%)$ & $39(3.8 \%)$ & \\
\hline Overweight & $190(17.5 \%)$ & $7(0.7 \%)$ & \\
\hline Obese & 89 (8.2\%) & $12(1.2 \%)$ & \\
\hline Body dissatisfaction & & & $0.018^{\mathrm{b}}$ \\
\hline Low & $185(17.1 \%)$ & $215(21.0 \%)$ & \\
\hline Moderate & $414(38.3 \%)$ & $408(39.8 \%)$ & \\
\hline Extreme & $482(44.6 \%)$ & 402 (39.2\%) & \\
\hline High risk for eating disorders & & & $0.002^{\mathrm{b}}$ \\
\hline Yes & $75(6.9 \%)$ & $40(3.9 \%)$ & \\
\hline No & 1,012 (93.1\%) & $990(96.1 \%)$ & \\
\hline Depression & & & 0.527 \\
\hline Yes & 325 (29.9\%) & $32 ।(31.2 \%)$ & \\
\hline No & 762 (70.1\%) & 709 (68.8\%) & \\
\hline
\end{tabular}

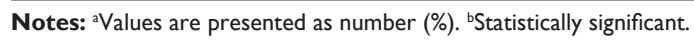

Abbreviation: $y$, years.

Table 3 Factors associated with body image distortion

\begin{tabular}{|c|c|c|}
\hline \multirow[t]{2}{*}{ Variables } & \multicolumn{2}{|c|}{ Controls versus subjects with body image distortion } \\
\hline & OR $(95 \% \mathrm{Cl})^{\mathrm{a}}$ & P-value \\
\hline \multicolumn{3}{|c|}{ Age, y (ref: I3-14) } \\
\hline $15-16$ & $1.31(1.02-1.54)$ & $0.03 I^{b}$ \\
\hline \multicolumn{3}{|l|}{ Sex (ref: female) } \\
\hline Male & $1.55(1.28-1.89)$ & $<0.00 \mathrm{I}^{\mathrm{b}}$ \\
\hline \multicolumn{3}{|c|}{ Current weight status (ref: normal weight) } \\
\hline Underweight & $1.25(0.79-1.98)$ & 0.337 \\
\hline Overweight & $33.27(|5.52-7| .35)$ & $<0.00 \mathrm{I}^{\mathrm{b}}$ \\
\hline Obese & $9.37(5.06-17.34)$ & $<0.00 \mathrm{I}^{\mathrm{b}}$ \\
\hline \multicolumn{3}{|c|}{ Body dissatisfaction (ref: low) } \\
\hline Moderate & I. $14(0.89-1.48)$ & 0.301 \\
\hline Extreme & $1.16(0.89-1.52)$ & 0.277 \\
\hline \multicolumn{3}{|c|}{ High risk for eating disorders (ref: no) } \\
\hline Yes & $1.69(1.11-2.58)$ & $0.015^{\mathrm{b}}$ \\
\hline
\end{tabular}

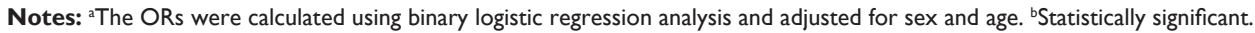

Abbreviations: $\mathrm{Cl}$, confidence interval; OR, odds ratio; $y$, years; ref, reference. 
A total of $5.4 \%(\mathrm{n}=115)$ adolescents were involved in high risk for EDs (EAT-26 scores $\geq 20$ ). There were no differences in prevalence of high risk for EDs by age (13-14 years: 5.0\%, 15-16 years: $6.3 \%$ ) or sex (boys: 5.5\%, girls: 5.3\%).

\section{Discussion}

In the present study, body image distortions were found in $51.3 \%$ of adolescents from the 13-16 year community sample. There were significant differences in prevalence of body image distortion by age (13-14 years: $49.7 \%$, 15-16 years: $54.8 \%$ ) and sex (boys: $55.3 \%$, girls: $45.2 \%$ ). Body image distortion might differ both quantitatively and qualitatively according to the age and sex of individuals and the cognitive developmental status in adolescents. Jackson and $\mathrm{Chen}^{26}$ found that sociocultural effects (ie, appearancebased pressure from family, peers, and media; teasing; and comparison) may be salient influences on a range of body image disturbances of Chinese male adolescents. ${ }^{26}$ Also, in Korean male adolescents, media messages that promote thinness (eg, male Korean pop stars are skinny and youthful), frequent appearance comparisons, and a desire to be thinner may affect boys' body image distortion. Sex or cultural differences associated with body image distortion during adolescence are not well understood, and further research in detail to investigate what exactly is associated with the risk of boys is needed.

There is a significant association between body image distortion and high risk for EDs. Previous studies reported that body image distortion and body dissatisfaction in EDs are risk factors for relapse after weight recovery. ${ }^{27,28}$ In addition, research on body image distortion in adolescents has focused on the predictive value for EDs. ${ }^{29}$ Adolescents with body image distortion were more likely to develop disturbed eating attitudes and behaviors. ${ }^{30}$ In this study, body image distortion was associated with overweight or obesity and body dissatisfaction. The study of the body image distortion in obese individuals has yielded inconsistent findings, and there are findings to support three different conclusions: obese individuals overestimate, underestimate, and are accurate regarding their body size estimation. ${ }^{31}$ Body image distortion and related factors such as body dissatisfaction and obesity have also been associated with low self-esteem. Self-esteem is an important psychological construct in adolescence, and poor self-esteem leads to feelings of inadequacy and worthlessness. ${ }^{32-34}$ In adolescence, low self-esteem increases vulnerability to pressures around the body and predicts body image distortion and body dissatisfaction over time, and may also affect eating attitudes and behaviors. This study is a cross-sectional study; therefore, a causal relationship between body image distortion and related factors, such as disturbed eating attitudes and behaviors, obesity, body dissatisfaction, and self-esteem is difficult to verify.

The present study had several limitations. Body image distortion was assessed via self-reporting by the subjects, and more structured clinical measures are needed to more accurately evaluate subjects' body image distortion. High risk for EDs and depression were also determined from self-reported data. Self-report measures may lead to under-reporting or underestimation of symptoms. The target schools were conveniently selected, and therefore the study findings may not be representative of all Korean adolescents. The cross-sectional nature of the study design limited the interpretation of the results and was not optimal for the investigation of the direction of causal inference. These findings should be considered as preliminary findings, and clarification of the direction of the relationship using prospective research is needed in order to contribute to understanding of the related area of body image distortion in adolescence.

\section{Conclusion}

In conclusion, body image distortion among Korean adolescents is common. It is associated with various factors such as sex, age, disturbed eating attitudes and behaviors, and body dissatisfaction. In particular, body image distortion in adolescents is associated with high risk for EDs. Increased awareness among parents, educators, and public health officials and a comprehensive approach considering all of this are needed.

\section{Acknowledgment}

This work was supported by a research grant of Jeju National University in 2010.

\section{Disclosure}

The authors report no conflicts of interest in this work.

\section{References}

1. Kang MH, Choue RW. Relationships of body image, body stress and eating attitude, and dietary quality in middle school girls based on their BMI. Korean J Nutr. 2010;43:285-293.

2. Gaudio S, Quattrocchi CC. Neural basis of a multidimensional model of body image distortion in anorexia nervosa. Neurosci Biobehav Rev. 2012;36:1839-1847.

3. Thompson JK, Coovert MD, Richards KJ, et al. Development of body image, eating disturbance, and general psychological functioning in female adolescents: covariance structure modeling and longitudinal investigations. Int J Eat Disord. 1995;18:221-236.

4. American Psychiatric Association. Diagnostic and Statistical Manual of Mental Disorders, Text Revision. 4th ed. Washington, DC: American Psychiatric Association; 2000. 
5. Whitaker A, Davies M, Shaffer D, et al. The struggle to be thin: a survey of anorexic and bulimic symptoms in a non-referred adolescent population. Psyhol Med. 1989;19:143-163.

6. Rastman M, Gillberg C, Garton M. Anorexia nervosa in a Swedish urban region: a population based study. Br J Psychiatry. 1989;155: 642-646.

7. Rathner G, Messner K. Detection of eating disorders in a small rural town: an epidemiological study. Psyhol Med. 1993;23:175-184.

8. Garfinkel PE, Lin E, Goering P, et al. Bulimia nervosa in a Canadian community sample: prevalence and comparison of subgroups. Am J Psychiatry. 1995;152:1052-1058.

9. Santonastaso P, Zanetti T, Sala A, et al. Prevalence of eating disorders in Italy: a survey on a sample of 16-year-old female students. Psychother Psychosom. 1996;65:158-162.

10. Sullivan PF. Mortality in anorexia nervosa. Am J Psychiatry. 1995;152:1073-1084.

11. Yoo WS, Kim YN. A study in eating disorders and its related factors in high school girls. Korean J Community Nutr. 2004;9:274-284.

12. Koff E, Rierdan J. Advanced pubertal development and eating disturbance in early adolescent girls. J Adolesc Health. 1993;14:433-439.

13. Makino M, Tsuboi K, Dennerstein L. Prevalence of eating disorders: a comparison of Western and non-Western countries. Med Gen Med. 2004;6:49.

14. Yang SJ, Kim JM, Yoon JS. Disturbed eating attitudes and behaviors in South Korean boys and girls: a school-based cross-sectional study. Yonsei Med J. 2010;51:302-309.

15. Tsai MR, Chang YJ, Lien PJ, et al. Survey on eating disorders related thoughts, behaviors and dietary intake in female junior high school students in Taiwan. Asia Pac J Clin Nutr. 2011;20:196-205.

16. Tam CK, Ng CF, Yu CM, et al. Disordered eating attitudes and behaviours among adolescents in Hong Kong: prevalence and correlates. J Paediatr Child Health. 2007;43:811-817.

17. Mak KK, Lai CM. The risks of disordered eating in Hong Kong adolescents. Eat Weight Disord. 2011;16:e289-e292.

18. Moon JS, Lee SY, Nam CM, et al. 2007 Korean National Growth Charts: review of developmental process and an outlook. Korean J Pediatr. 2008;51:1-25.

19. Garner DM, Garfinkel PE. The Eating Attitudes Test: an index of the symptoms of anorexia nervosa. Psychol Med. 1979;9:273-279.

20. Garner DM, Olmstead BY, Garfinkel PE. The Eating Attitudes Test: psychometric feature and clinical correlates. Psychol Med. $1982 ; 12: 871-878$
21. Sorensen TIA, Stunkard AJ, Teasdale TW, et al. The accuracy of reports of weight: Children's recall of their parents' weights 15 years earlier. Int J Obesity. 1983;7:115-122.

22. Won JW, Bae JM. Quick measurement of an obesity level with somatotype drawings in outpatient clinic setting in Korea. J Korean Acad Fam Med. 1996;17:332-338.

23. Choi JH, Ahn DH, Nam JH, et al. Reliability and validity of Eating Attitude Test-26 for Korean adolescents. Korean J Child and Adol Psychiatry. 1998;9:91-97.

24. Beck AT, Ward CH, Mendelson M, et al. An inventory for measuring depression. Arch Gen Psychiatry. 1961;4:561-571.

25. Shin MS, Park KB, Oh KJ, et al. A study of suicidal ideation among high school students: the structural relation among depression, hopelessness, and suicidal ideation. Korean J Clin Psychol. 1990;9:1-19.

26. Jackson T, Chen H. Sociocultural influences on body image concerns of young Chinese males. J Adolesc Res. 2008;23:154-171.

27. Keel PK, Dorer DJ, Franko DL, et al. Postremission predictors of relapse in women with eating disorders. Am J Psychiatry. 2005;162: 2263-2268.

28. Freeman RJ, Beach B, Davis R, et al. The prediction of relapse in bulimia nervosa. J Psychiatr Res. 1985;19:349-353.

29. Stice E, $\mathrm{Ng} \mathrm{J}$, Shaw H. Risk factors and prodromal eating pathology. $J$ Child Psychol Psychiatry. 2010;51:518-525.

30. Neumark-Sztainer D, Paxton SJ, Hannan PJ, et al. Does body satisfaction matter? Five-year longitudinal associations between body satisfaction and health behaviors in adolescent females and males. $J$ Adolesc Health. 2006;39:244-251

31. Schwartz MB, Brownell KD. Obesity and body image. Body Image. 2004;1:43-56.

32. Youngs GA Jr, Rathge R, Mullis R, et al. Adolescent stress and self-esteem. Adolescence. 1990;25:333-341.

33. Murray K, Rieger E, Byrne D. A longitudinal investigation of the mediating role of self-esteem and body importance in the relationship between stress and body dissatisfaction in adolescent females and males. Body Image. 2013;10:544-551.

34. Paxton SJ, Eisenberg ME, Neumark-Sztainer D. Prospective predictors of body dissatisfaction in adolescent girls and boys: a five-year longitudinal study. Dev Psychol. 2006;42:888-899.
Neuropsychiatric Disease and Treatment

\section{Publish your work in this journal}

Neuropsychiatric Disease and Treatment is an international, peerreviewed journal of clinical therapeutics and pharmacology focusing on concise rapid reporting of clinical or pre-clinical studies on a range of neuropsychiatric and neurological disorders. This journal is indexed on PubMed Central, the 'PsycINFO' database and CAS,

\section{Dovepress}

and is the official journal of The International Neuropsychiatric Association (INA). The manuscript management system is completely online and includes a very quick and fair peer-review system, which is all easy to use. Visit http://www.dovepress.com/testimonials.php to read real quotes from published authors. 